\title{
DIREITOS HUMANOS E COMÉRCIO INTERNACIONAL: REFLEXÕES SOBRE A "CLÁUSULA SOCIAL"
}

\author{
Alberto do Amaral Júnior \\ Professor Doutor do Departamento de Direito Internacional da \\ Faculdade de Direito da Universidade de São Paulo
}

\begin{abstract}
Resumo:
O presente artigo analisa o impacto da violação de Direitos Trabalhistas para o comércio internacional. A tese aqui sustentada considera que este tema, de profunda relevância para a competitividade entre os países, deve ter como foro privilegiado de discussão a OIT, já que o seu tratamento no âmbito da OMC oculta indisfarçáveis reivindicações protecionistas.
\end{abstract}

Abstract:

The present article analyzes the impact of the violation of labor laws for the international trade. The thesis here sustained it considers that this theme, of deep relevance for the competitiveness among the countries, should have the OIT as privileged forum of discussion, since your treatment in the ambit of OMC hides unconcealable revindications protectionists.

Unitermos: Direitos Humanos; comércio internacional.

Robert Gilpin, em livro já clássico, assinala que o comércio internacional é o mais antigo e o mais importante vínculo econômico entre as nações. Ao lado da guerra, o comércio ocupa posição central entre os fenômenos da vida internacional. ${ }^{1}$

A criação de impostos sobre as operações mercantis foi, ao longo do tempo, a principal fonte de receita utilizada pelos governos. Impérios nasceram e se desenvolveram em razão do controle exercido sobre rotas comerciais da África e da Ásia. No século XX, a tributação da atividade mercantil não tem o mesmo significado econômico, não-obstante continue a ser meio de financiamento da maior relevância para muitos países subdesenvolvidos e em desenvolvimento.

1. Robert Gilpin, with the assistance of Jean M. Gilpin, The Political Economy of International Relations, Princeton, New Jersey, Princeton University Press, copyright 1987, p. 171. 
Gilpin enumera os seguintes efeitos da expansão comercial:

1. difusão tecnológica que traz maior bem-estar aos indivíduos;

2. aumento da demanda que estimula o crescimento e a eficiência geral da economia;

3. ampliação dos mercados, economias de escala, alto retorno dos investimentos;

4. alargamento da margem de escolha oferecida aos consumidores;

5. redução do preço dos inputs, tais como matérias-primas e componentes manufaturados, com conseqüências no custo global da produção. ${ }^{2}$

Esta visão positiva do comércio não é, contudo, aceita por todas as correntes do pensamento econômico. A perspectiva varia de acordo com a posição adotada sobre o papel assumido pelo Estado, em face das transações econômicas internacionais. Três grandes famílias de teorias disputam a primazia na explicação das causas, dos objetivos e consequiências do comércio internacional, a saber: os liberais (ou neoclássicos), os mercantilistas (ou neomercantilistas) e os estruturalistas, incluindo-se nesta categoria os partidários da teoria da dependência. ${ }^{3}$ A diferença que as separa repousa no valor que consideram prioritário e no defeito que buscam corrigir mediante a intervenção da autoridade política.

Para o pensamento liberal, comércio e paz estão indissociavelmente ligados. O comércio conduz à paz ao criar vínculos positivos entre as pessoas e ao promover a harmonia dos interesses entre as sociedades. Os liberais acreditam que a criação de riquezas é obtida pela combinação eficiente dos fatores de produção. A eficiência surge, nesse sentido, como valor mais importante, concretizado pelas políticas que suprimem as restrições ao funcionamento do mercado.

O comércio livre tende a elevar o nível de bem-estar dos indivíduos e das nações. A especialização, efeito da divisão do trabalho, origina o aumento da riqueza, pois cada país produz os bens que dispõem de maior vantagem comparativa no comércio internacional.

2. Robert Gilpin, op. cit., pp. 171-172.

3. Susan Strange, States and Markets, London, Pinter Publishers, 1988, p. 174. 
A prática do comércio livre não traz, necessariamente, ganhos imediatos, mas apenas benefícios potenciais. A expansão do bem-estar se dará no longo prazo, com a adoção de políticas de especialização baseadas na lei das vantagens comparativas. $^{4}$

A liberdade de comércio proporciona ganhos absolutos, mas alguns ganharão relativamente mais do que outros, devido à sua maior eficiência e capacidade natural.

Os mercantilistas e estruturalistas consideram o comércio pernicioso, porque a especialização econômica e a interdependência tornam os Estados inseguros, dependentes e vulneráveis aos acontecimentos externos. O comércio é visto como fonte de tensões políticas e econômicas que, em última instância, pode limitar a atuação dos governos nos assuntos domésticos. ${ }^{5}$

Para os mercantilistas a busca de segurança é o valor central diante da insegurança que domina as relações internacionais. A função do governo é afastar os riscos que o funcionamento do mercado mundial impõe à sobrevivência do Estado. A coesão social, na óptica mercantilista, é o fundamento das instituições políticas, o que justificaria sacrificar outros valores para a sua manutenção, ainda que os custos fossem comparáveis aos que o Estado teria para repelir o invasor externo. ${ }^{6}$

Alexander Hamilton, um dos primeiros mercantilistas, escrevendo em pleno século XVIII, sustentava que o governo pode transformar a natureza da economia de um país e sua posição no cenário internacional ao executar as medidas adequadas a esta finalidade. Hamilton imaginava que a economia não é uma realidade em si, que não se amolda aos objetivos políticos de ordem geral. A tarefa de construção do Estado sobrepõe-se aos propósitos dos agentes econômicos privados, determinando a subordinação destes às metas fixadas pelo governo.

Na Alemanha do século XIX, Friedrich List, criticando a economia política inglesa, dizia não haver uma divisão "natural" e imutável do trabalho com base na lei das vantagens comparativas. Para ele, a divisão do trabalho tinha como causa a cristalização do poder político e econômico em dado momento histórico. ${ }^{7}$

\footnotetext{
4. Robert Gilpin, op. cit., pp. 173-174.

5. Robert Gilpin, op. cit., p. 171.

6. Susan Strange, op. cit., pp. 174-175.

7. Robert Gilpin, op. cit., p. 181.
} 
Ainda hoje, os mercantilistas indicam que a lei das vantagens comparativas é a racionalização da divisão do trabalho atualmente existente, sugerindo a formulação e execução de planos consistentes de apoio ao setor industrial. Ressaltam que ao ignorar a função das políticas industriais, o livre comércio expõe a economia às vicissitudes e instabilidades do mercado mundial. Enquanto os liberais enaltecem as virtualidades da especialização, os mercantilistas destacam que ela reduz a flexibilidade, aumenta a vulnerabilidade da economia aos acontecimentos indesejáveis, subordina o mercado interno à economia internacional, ameaçando a indústria doméstica da qual dependem o emprego, a segurança nacional e outros valores dignos de proteção. ${ }^{8}$

Os estruturalistas concentram atenção particular aos problemas relativos à Justiça do sistema econômico. O mercado não é neutro, imune à dominação e ao poder.

O crescimento econômico desigual das diferentes partes do mundo é prejudicial aos países da África, Ásia e América Latina. Este fato requer políticas de assistência ao Terceiro Mundo com o fito de assegurar maior equilíbrio do sistema econômico internacional. Mais igualdade exige políticas compensatórias específicas, como, por exemplo, as que concedem facilidades de crédito, preferências comerciais e ajuda aos países pobres.

Nenhuma nação parece haver optado em definitivo por uma dessas visões, excluindo terminantemente as demais. A escolha do ponto de vista que informará a condução da economia altera-se, conforme a conjuntura, em virtude dos interesses domésticos e das condições prevalecentes na realidade internacional. A experiência dos anos 90 atesta, principalmente após o término bem-sucedido da Rodada Uruguai, cujos resultados estão em sintonia com a desregulação e internacionalização dos mercados, o predomínio do livre comércio na orientação das políticas econômicas nacionais.

$\mathrm{Na}$ esfera internacional os benefícios oriundos da liberdade de comércio pressupõem a ordenação do mercado global por meio de marcos jurídicos institucionais, acordados em negociações multilaterais, que garantam tanto a previsibilidade de expectativas dos agentes econômicos quanto a solução de conflitos entre as partes. O sistema regulatório assim criado deve especificar o domínio do permitido, bem como as condutas nocivas ao comércio internacional.

8. Robert Gilpin, op. cit., p. 183. 
A palavra "direito" pode ser usada em sentido fraco e em sentido forte. A primeira acepção designa a exigência de direitos futuros, ou seja, a proteção futura de certo bem. Já a segunda indica a proteção efetiva desse bem e pode ser reivindicada perante os tribunais para reparar abusos e punir os culpados. ${ }^{9}$ Esta observação é importante porque, antes de receber consagração legislativa nos textos legais, os Direitos Humanos constituíam exigência de proteção futura de certo bem. ${ }^{10}$

A expressão Direitos Humanos supõe, no dizer de Chaïm Perelman, que toda pessoa merece respeito como sujeito moral, livre, autônomo e responsável. ${ }^{11} \mathrm{O}$ respeito à dignidade humana é, portanto, a condição necessária para elaborar uma concepção jurídica dos Direitos Humanos. Esta, por seu turno, realizase apenas mediante um sistema jurídico que imponha a cada ser humano, seja em relação a si próprio, seja no tocante aos outros homens e ao poder incumbido de proteger tais direitos, a obrigação de respeitar a dignidade humana. ${ }^{12}$

Com isso, procura-se evidenciar que a obrigação de respeitar os Direitos Humanos pertence não-só aos indivíduos, mas também ao Estado. A limitação do poder do Estado não se opera com êxito fora dos quadros do Estado de Direito e da independência do Judiciário. Sem regras que disciplinem as condições para a ação das autoridades e que regulem os procedimentos que nortearão o seu comportamento, não é possível a efetiva proteção dos Direitos Humanos.

O reconhecimento do valor da pessoa, a despeito das divergências em torno das aplicações concretas desse princípio, permitiu, a partir de 1945, a criação de um sistema internacional de tutela dos Direitos Humanos. O período posterior à Segunda Guerra Mundial caracterizou-se pela proliferação dos direitos do homem de três modos diferentes:

a. aumentou a quantidade de bens merecedores de tutela;

b. foi estendida a titularidade de alguns direitos a sujeitos diversos do homem;

9. Norberto Bobbio, "Direitos do Homem e Sociedade", in A Era dos Direitos. Tradução de Carlos Nelson Coutinho, Rio de Janeiro, Editora Campus, 1992, p. 67.

10. Norberto Bobbio, op. cit., pp. 67-83.

11. Chaïm Perelman, Ética e Direito. Tradução de Maria Ermantina Galvão G. Pereira, São Paulo, Martins Fontes, 1996, pp. 400-401.

12. Chaïm Perelman, op. cit., pp. 400-401. 
c. o homem não é mais considerado ente genérico, mas em vista da especificidade que possui como criança, velho, doente, etc. ${ }^{13}$

Bobbio observa que com relação ao primeiro processo verificou-se a passagem dos direitos de liberdade - liberdade de religião, de opinião, de imprensa, etc. para os direitos políticos e sociais, que requerem a intervenção direta do Estado. Relativamente ao segundo processo ocorreu a passagem do indivíduo humano para sujeitos diferentes do indivíduo, de que são exemplos a família, as minorias étnicas e religiosas, e mesmo toda a humanidade. Quanto ao terceiro processo, houve a passagem do homem genérico para o homem específico, classificado com base em múltiplos critérios de diferenciação (sexo, idade, condições físicas). ${ }^{14}$

No campo dos direitos econômicos e sociais inúmeras convenções, além de os consagrar expressamente, consideraram a sua efetivação essencial para a plena dignidade humana. Esta concepção, presente na Declaração Universal dos Direitos do Homem e do Cidadão, de 1948, foi corroborada pelo Pacto dos Direitos Econômicos, Sociais e Culturais, de 1966, e pela atividade da OIT que, desde a sua criação, em 1919, tem-se ocupado com a formulação, por meio de convenções, recomendações, códigos e diretrizes, das regras trabalhistas de alcance geral.

$\mathrm{O}$ vínculo entre Direitos Humanos e comércio internacional residiria na ligação cada vez mais perceptível entre as vantagens comparativas em matéria comercial e as discrepâncias de regimes trabalhistas entre os países, muitas das quais resultam da violação de direitos constantes de tratados e convenções internacionais. Longas jornadas de trabalho, baixos salários, utilização da mão-de-obra infantil e condições de trabalho inadequadas seriam formas de "dumping social" acarretando o aumento das exportações devido à queda dos custos de produção.

O tema da cláusula social, como ficou conhecida nas discussões internacionais a associação entre Direitos Trabalhistas e comércio, envolve pelo menos quatro dimensões principais:

a. a preocupação com as práticas desleais de comércio;

13. Norberto Bobbio, op. cit., p. 68.

14. Norberto Bobbio, op. cit., p. 68. 
b. a busca de soluções que reduzam os níveis de desemprego nas economias que sofrem as conseqüências do processo de globalização;

c. a expansão do desconforto ético e moral com a violação dos Direitos Humanos;

d. o temor de que tais argumentos favoreçam o protecionismo, afetando as exportações dos países em desenvolvimento.

Encontra-se superada a fase em que as negociações sobre política comercial se concentravam, exclusivamente, no impacto que o comércio exercia no interior das fronteiras nacionais, o que colocava no centro do debate a questão das barreiras alfandegárias e não-alfandegárias. Os problemas comerciais mais relevantes requerem agora a capacidade de lidar com a profunda e complexa integração entre as múltiplas políticas governamentais. Este fato realça a estreita conexão entre mecanismos de tutela dos Direitos Humanos, regimes trabalhistas e políticas comerciais.

O reflexo das disparidades de regimes trabalhistas no comércio internacional passou a merecer atenção em virtude do entrelaçamento dos mercados, facilitado pelo fenômeno da globalização econômica, pelas altas taxas de desemprego no mundo desenvolvido e pelo desconforto moral provocado pela obtenção de vantagens comparativas graças a condições indignas e até mesmo degradantes de trabalho.

A União Européia e os EUA têm acusado vários países subdesenvolvidos e em desenvolvimento de praticarem "dumping social" ao infringir Direitos Trabalhistas básicos na tentativa de elevar a competitividade externa. Alega-se, sob esse aspecto, que a vantagem derivada da redução do custo de mão-de-obra é injusta, desvirtuando o comércio internacional. Sustenta-se, ainda, que a harmonização do fator trabalho é indispensável para evitar distorções num mercado que se globaliza. ${ }^{15}$

Os países em desenvolvimento, por outro lado, afirmam que a acusação de "dumping social" configura uma nova modalidade de protecionismo, pois os níveis de remuneração do trabalho estão condicionados pelo grau de

15. Celso Lafer, "Dumping Social", in Direito e Comércio Internacional: Tendências $e$ Perspectivas, Estudos em homenagem ao Prof. Irineu Strenger, coordenadores: Luiz Olavo Baptista, Hermes Marcelo Huck, Paulo Borba Casella, São Paulo, Editora LTr, 1994, p. 162. 
desenvolvimento dos países e, dentro deles, de suas regiões, Estados e Municípios. ${ }^{16}$ Com efeito, por trás da pretensa defesa de padrões trabalhistas mais eqüitativos haveria tão-somente o objetivo de estimular a exportação de bens tecnologicamente avançados para as nações menos desenvolvidas, restringindo-se, ao mesmo tempo, as exportações destas para as economias industrializadas.

Não resta dúvida de que a condenação do "dumping social" oculta indisfarçáveis motivações protecionistas. A pressão dos sindicatos trabalhistas, agravada pelos índices de desemprego que atingem ponderáveis parcelas da população, tem sido fator decisivo na atitude que os governos norte-americano e europeus assumiram nesse particular. Não se pode negar, contudo, que o tema do "dumping social" a par de notórios interesses protecionistas, indica preocupações éticas na área dos Direitos Humanos.

Estamos nesse ponto diante do problema relativo aos limites éticos da competição, isto é, da indagação acerca dos parâmetros que estabelecem e definem os limites da esfera dentro da qual os agentes econômicos irão atuar. É legítima a utilização de quaisquer métodos para a produção dos bens? A concorrência admite o emprego de todos os meios necessários para sobrepujar os competidores?

Na verdade, a observação da vida econômica mostra que as sociedades costumam impor restrições morais e legais ao funcionamento do mercado. Os indivíduos não são inteiramente livres para celebrar qualquer tipo de contrato. Michael Walzer denomina tais restrições de blocked exchanges, que incluiriam, nos EUA, desde hipóteses que abrangem a proibição do comércio de seres humanos e de cargos públicos às leis trabalhistas, que disciplinam o limite máximo da jornada de trabalho. ${ }^{17}$

As concepções morais e legais fixam o âmbito do aceitável ao estipular os critérios que determinam o lícito e o ilícito nas operações de troca. Tais concepções delimitam, em última instância, a esfera de legitimidade das transações econômicas. Encontram-se em geral refletidas nas normas que regulam a produção dos bens e a execução dos serviços.

16. Celso Lafer, op. cit., p. 162.

17. Dani Rodrik, Has Globalization Gone Too Far?, Washington, DC, Institute for International Economics, 1997, p. 35.

Vide Michael Walzer, Spheres of Justice: A Defense of Pluralism an Equality, New York, Basic Books, 1983. 
No cenário internacional, a Declaração Universal dos Direitos do Homem e do Cidadão, de 1948, o Pacto dos Direitos Civis e o Pacto dos Direitos Econômicos, Sociais e Culturais, além da grande quantidade de tratados que versam sobre questões específicas na área dos Direitos Humanos, não fazem outra coisa senão declarar que comportamentos são admitidos e que condutas devem merecer condenação geral. Em se tratando de direitos econômicos e sociais, a OIT, com o fím de designar o que seja moralmente aceitável na esfera do trabalho, tomou a iniciativa de definir as convenções que expressam "Direitos Humanos básicos" São elas as convenções sobre liberdade de organização e de reivindicação coletiva, sobre trabalho forçado, igualdade de remuneração e sobre a proibição de discriminação no emprego. Estas convenções estão entre as mais ratificadas e a elas a OIT dedica a maior atenção. Formam, em seu conjunto, um corpus de Direitos Trabalhistas internacionalmente reconhecidos.

Nos dias atuais, o interesse despertado pelo tema da "cláusula social" encerra indiscutivelmente preocupações justificadas com a proteção dos Direitos Humanos. A ineficácia dos direitos econômicos e sociais em grande parte das regiões do globo acarreta a falta de liberdade de organização sindical, o emprego de mão-de-obra infantil, as discriminações e o recurso ao trabalho forçado, provocando visível desconforto junto à opinião pública internacional. Esta maior sensibilidade ética muitas vezes se traduz tanto em pressão para que os governos imponham barreiras à importação dos bens assim produzidos, fato que exprime postura nitidamente protecionista, quanto para que a comunidade internacional crie mecanismos institucionais apropriados para sancionar os Estados que transgridam os Direitos Humanos.

Datam do final do século XIX as primeiras tentativas de relacionar Direitos Humanos e comércio internacional. O empenho verificado para prescrever o tráfico internacional de escravos e para banir o trabalho forçado insere-se nessa perspectiva.

O Tratado de Versalhes, produto da Conferência de Paz de Paris, de 1919, obrigava os signatários a envidar esforços para assegurar e manter condições justas e humanas de trabalho na produção dos bens que integram o comércio internacional. A Carta de Havana, elaborada pelos participantes da Conferência Internacional sobre o Comércio e o Emprego, que previu a criação da Organização Internacional do Comércio, continha dispositivo específico em que os Estados, após 
reconhecer que as condições iníqüas de trabalho afetam negativamente as operações comerciais, comprometiam-se a eliminá-las em seu território.

A Organização Internacional do Comércio, porém, jamais entrou em funcionamento, dada a recusa do Congresso dos EUA em aprovar o ingresso do país naquela organização. A crença de que a OIC substituiria o GATT acabou por impedir a inclusão do capítulo trabalhista da Carta de Havana entre as normas do Acordo Geral de Comércio e Tarifas.

Desde então, o Governo norte-americano tem procurado, sem sucesso, corrigir essa omissão. ${ }^{18}$ Em 1983 foi rejeitada a proposta dos EUA de inserir no GATT uma cláusula sobre Direitos Trabalhistas, haja vista a falta de disposição das partes para definir o que se deve entender por práticas desleais nesse setor. Em 1979, durante a Rodada Tóquio, os EUA propuseram a adoção de um código de Direitos Trabalhistas, iniciativa que recebeu o apoio somente de alguns governos escandinavos.

As pressões sindicais somadas às dificuldades encontradas para incorporar ao GATT regras trabalhistas deram origem a movimentos que propugnaram pela introdução de tais normas na legislação comercial americana. Algumas leis instituíram a possibilidade de outorga de concessões comerciais aos países que adotarem regimes trabalhistas equiitativos. Um dos primeiros diplomas legais a consagrar essa previsão foi o Caribean Basis Economic Recovery Act (CBERA), que isenta dos tributos de importação numerosos produtos originários de países da bacia do Caribe. A referida isenção está condicionada ao fato de o Estado beneficiário assegurar o exercício de liberdade de associação e de participação em negociações coletivas, proibir o trabalho forçado e o uso abusivo da mão-de-obra infantil.

Merece destaque, também, o Generalized System of Preferences (GSP), cuja finalidade é de conceder benefícios fiscais a produtos provenientes dos países em desenvolvimento. O Trade and Tariff Act, de 1984, adicionou os Direitos Trabalhistas reconhecidos internacionalmente entre os fatores que afetam a outorga de tratamento privilegiado. Já o Overseas Private Investment Corportation Act (OPIC) dispõe sobre os projetos de inveștimentos privados nos países em

18. R. Michael Gadbaw and Michael T. Medwig, "Multinational Enterprises and Insternational Labor Standards Which Way for Development and Jobs?" in Human Rights, Labor Rights, and International Trade, Edited by Lance A. Compa and Stephen F. Diamond, University of Pennsylvania Press, USA, 1996, p. 143. 
desenvolvimento, garantindo o investidor norte-americano contra eventuais riscos políticos. Em 1985 foram acrescidos os Direitos Trabalhistas aos requisitos para a autorização de investimentos no Exterior.

Os críticos do OPIC apontam os efeitos negativos das suas restrições para os países em desenvolvimento. Salientam que as empresas norte-americanas no Exterior em geral pagam salários mais elevados, fornecem maiores benefícios e níveis superiores de segurança no trabalho que os oferecidos pelas empresas locais. ${ }^{19}$ A não-execução de projetos em razão do descumprimento dos Direitos Trabalhistas pode privar o Estado receptor de avanços na área social, além, evidentemente, de impedir que as nações em desenvolvimento obtenham maiores benefícios comerciais, atraiam novas empresas e possam desenvolver novas tecnologias. ${ }^{20}$

O Direito norte-americano vale-se, também, da noção de práticas desleais para a aplicação de sanções comerciais aos países que mantêm regimes trabalhistas abaixo dos níveis considerados aceitáveis. O Omnibus Trade and Competitiveness Act, de 1988 (OTCA), introduziu modificação na Seção 301 do Trade Act de 1974, a qual autoriza o US Trade Representative (USTR) a adotar medidas contra qualquer ato, política ou prática que limite ou restrinja o comércio dos EUA com outras nações. Esta norma tem sido usada para impor sanções aos Estados que vedam o livre acesso dos produtos americanos.

O OTCA incluiu o respeito aos Direitos Trabalhistas entre as causas que ensejam a atuação do USTR.

Importa frisar, porém, que a prática a que alude a seção 301 não será reputada unreasonable se o USTR concluir que o país estrangeiro tenha tomado ou esteja tomando providências que demonstrem progressos significativos na salvaguarda dos Direitos Humanos, ou se a mesma não-prejudicar o desenvolvimento econômico dos EUA.

O North American Agreement on Labour Corporation (NAALC), firmado, em 1993, pelos EUA, México e Canadá, no contexto do NAFTA, determinou que o descumprimento dos Direitos Trabalhistas em certas áreas pode

19. R. Michael Gadbaw and Michael T. Medwig, op. cit., p. 149.

20. R. Michael Gadbaw and Michael T. Medwig, op. cit., p. 149.

Vide Drusilla K, Brown, Alan V. Deardorff, Robert M. Stern, "International Labor Standards and Trade: A Theoretical Analysis", in Fair Trade Harmonization - Prerequisites for Free Trade? Edited by Jagdish Bhagwati, Robert E. Hudec, The MIT Press, Cambridge, Massachusetts, London, England, 1996. 
desencadear a aplicação de sanções comerciais. $\mathrm{O}$ acordo parte da premissa de que a desobediência aos padrões trabalhistas avençados caracteriza prática competitiva desleal.

A associação entre Direitos Trabalhistas e comércio promovida pela legislação interna norte-americana exemplifica o que recentemente vem sendo chamado de "unilateralismo agressivo" ou seja, a imposição de sanções comerciais aos Estados que não-respeitam alguns Direitos Trabalhistas básicos. A legislação americana, contudo, não-compreende os múltiplos aspectos admitidos internacionalmente como necessários para assegurar a tutela dos Direitos Trabalhistas. Uma das mais notáveis omissões refere-se à discriminação no emprego com base na raça, sexo, religião, opinião política, origem social ou nacionalidade. Deve-se notar, a este propósito, que os EUA ratificaram somente a Convenção 105 sobre a abolição do trabalho forçado, deixando de ratificar as demais convenções que a OIT incluiu no rol das que consagram Direitos Humanos básicos na área trabalhista. Além disso, a forma como os Direitos Trabalhistas se encontram regulados possibilita ampla margem de discricionariedade às autoridades administrativas, que podem escolher, em cada caso, o standard a ser aplicado.

Por último, o recurso ao unilateralismo para punir os países cujas exportações não se ajustam aos requisitos impostos pela legislação norte-americana é conseqüência direta do declínio econômico e comercial dos EUA, nas décadas de 70 e 80. Segundo Regis P Arslanian, em 1950 os EUA detinham 40,3\% do PNB mundial. Em 1980 esse percentual caiu para 21,8\%. No mesmo período, a parcela da Europa subiu de 21,2 para 29,8, a do Japão de 1,6 para $8,8 \%$. A participação dos países em desenvolvimento elevou-se de 12,7 , em 1950, para 17,9, em $1980 .^{2 \mathrm{I}}$

Em 1950 os EUA exportavam o equivalente a 16,7\% do valor total das exportações mundiais, cifra que foi reduzida para 10,9, em 1980. Nesse período, as exportações européias cresceram de 33,4 para 40,4 , e as do Japão de 1,4 para $6,4 \% .^{22}$

21. Regis P. Arslanian, O Recurso à Seção 301 da Legislação de Comércio Norte-Americana e a Aplicação de seus Dispositivos contra o Brasil, Brasília, Instituto Rio Branco, 1994, p. 16

22. Regis P. Arslaniam, op. cit., p. 16.

Vide Philip Alston, "Labor Rights Provisions in U.S. Trade Law" "Aggressive Unilateralism?" in Human Rights, Labor Rights, and International Trade. Edited by Lance A. Compa and Stephen F. Diamond, University of Pennsylvania Press, USA, 1996.

Vide Corrado Pirzio - Birrolli, "A European View of the 1988 U.S. Trade Act and Section 301", in Jagdish Bhagwati, Aggressive Unilateralism, p. 261. 
O incremento das exportações japonesas e dos países recémindustrializados da Ásia e da América Latina, o aumento do defficit comercial americano, que passou de 36 bilhões de dólares (1,3\%) do PNB, em 1980, para 171 bilhões de dólares $(3,8 \%)$ do PNB, em 1987, a avidez pela conquista de novos mercados, a percepção de que os governos estrangeiros deveriam eliminar as barreiras em matéria de serviços, investimentos e propriedade intelectual, setores em que as vantagens competitivas dos EUA são mais pronunciadas, a preocupação em lançar uma nova rodada multilateral de negociações, devido às insuficiências dos instrumentos oferecidos pelo GATT, notadamente os mecanismos de solução de controvérsias, e a crença de que a deterioração da balança comercial resultava de práticas desleais adotadas por outros Estados, estimularam as reivindicações protecionistas por parte de sindicatos e entidades de classe. As mudanças na legislação comercial nos anos 70 e 80 coroada pela reforma em 1988, responsável pela modificação na seção 301, que tem sido denominada de "super 301 " e "especial $301 "$ refletiram o fortalecimento dos sentimentos protecionistas em voga na sociedade americana. O free trade cada vez mais cede lugar ao fair trade, concebido para reduzir o impacto da perda das vantagens competitivas dos EUA na economia mundial.

Durante os encontros preliminares que precederam o início da Rodada Uruguai, os EUA procuraram inserir o tema dos Direitos Trabalhistas na agenda de negociações. O delegado norte-americano ao Comitê preparatório afirmou, na oportunidade, que "os EUA não pretendiam impor o seu padrão salarial ao resto do mundo ou negar as vantagens comparativas legítimas das nações em desenvolvimento. Visam, antes, assegurar que a expansão comercial não é um objetivo em si mesmo, pois ela beneficia os trabalhadores em todos os países e contribui para a realização das finalidades do GATT" 23

Os países em desenvolvimento recusaram-se a iniciar qualquer discussão sobre padrões trabalhistas, mesmo diante da promessa de que os EUA nãoinvestigariam supostas violações desses direitos. A Declaração Ministerial de Marrakesh não fez qualquer menção aos Direitos Trabalhistas.

No âmbito da Organização Mundial do Comércio, OMC, o tema foi objeto de dois non papers apresentados, respectivamente, pelos EUA e pela Noruega. O documento americano sugere a criação de um grupo de trabalho para o 
exame de padrões trabalhistas essenciais, tais como o direito de organizar e reivindicar coletivamente, a proibição de trabalho forçado, a proibição de formas exploratórias do trabalho infantil e não-discriminação no emprego ou ocupação. ${ }^{24} \mathrm{O}$ documento da Noruega, por sua vez, manifesta a intenção de manter o diálogo sobre meios para elevar os padrões trabalhistas em nível mundial e sobre a contribuição do comércio para esse fim. ${ }^{25}$

Muitos países desenvolvidos, além de organizações internacionais de grande expressão, continuam a enfatizar a intrínseca relação entre comércio e Direitos Humanos. Publicado em 1980, o relatório da Comissão Brandt sobre as relações norte-sul destacou que a salvaguarda dos Direitos Trabalhistas é fator capaz de ampliar o comércio e incentivar o crescimento da economia. As recomendações apresentadas propunham que a introdução nas legislações internas dos standards aceitos pela comunidade internacional desempenharia papel relevante para evitar a competição desleal e promover a liberalização do comércio. O Banco Mundial, o FMI e o Programa das Nações Unidas para o Desenvolvimento têm demonstrado que a proteção dos Direitos Humanos deve ser levada em conta na concessão de empréstimos ao terceiro mundo.

Os países em desenvolvimento contestam tais argumentos, afirmando que essa vinculação constitui limitação inaceitável à sua soberania, impedindo que possam se beneficiar das vantagens comparativas resultantes dos baixos custos da mão-de-obra. Aduzem em apoio a esta tese que adotar os padrões trabalhistas europeus causaria a rigidez do mercado de trabalho, fato que na Europa concorreu para aumentar o desemprego e reduzir drasticamente as taxas de crescimento.

Mais do que tomar posição no debate que divide opositores e defensores da "cláusula social", convém assinalar alguns pontos fundamentais que o permeiam, apontando as tendências com maior probabilidade de se consolidar nos próximos anos. Ao contrário do que em princípio se imaginara, o custo da mão-deobra continua a representar fator relevante na competitividade das economias.

Baixos salários e o descumprimento dos Direitos Trabalhistas são importantes vantagens comparativas no comércio internacional. Essas vantagens não se manifestam apenas no comércio entre as nações desenvolvidas e em

24. Celso Lafer, A OMC e a Regulamentação do Comércio International: Uma Visão Brasileira, Porto Alegre, Livraria do Advogado Editora, 1998, p. 57.

25. Celso Lafer, op. cit., pp. 57-58. 
desenvolvimento. A presença no mercado internacional de produtos exportados por países asiáticos, que dispõem de regimes trabalhistas inferiores aos recomendados pela OIT, acentuou ainda mais o contraste entre condições de trabalho, chamando a atenção para o reflexo que provocam no intercâmbio entre as nações.

A globalização da economia pôs em evidência o conflito entre dois interesses dos trabalhadores: a preservação do emprego e a melhoria das condições de trabalho. Não se descarta a hipótese, diante do novo quadro que se esboça, caracterizado, de um lado, pela substituição do modelo fordista pelo "paradigma da especialização flexível da produção" e pelo acirramento da competição global, de outro, de que os trabalhadores renunciem a lutar por melhores condições de trabalho em troca da manutenção do emprego. Na busca frenética de novos mercados, muitos governos não-desejam abdicar das vantagens comerciais que advêm da redução do custo do fator trabalho, provocada pela violação das convenções internacionais.

A globalização econômica intensificou extraordinariamente a competição comercial: pequenas alterações de custo repercutem nas vantagens comparativas dos países, fato que as torna cada vez mais voláteis. Jagdish Bhagwati indica três fenômenos que constituem fontes de preocupação dos países desenvolvidos em face dos efeitos do processo de globalização:

1. A vulnerabilidade e a viabilidade internacional das economias refletem as novas vantagens comparativas, de natureza volátil e caleidoscópica. As empresas passam a observar o comportamento das competidoras estrangeiras para verificar se as diferenças em termos de políticas e instituições domésticas lhes conferem benefícios "indevidos", que configurariam unfair trade. A proliferação das reivindicações em favor do fair trade nos países desenvolvidos, visando harmonizar as políticas e instituições domésticas como pré-requisitos para o comércio livre, expressa o caráter caleidoscópico das novas vantagens comparativas.

2. O sentimento de insegurança econômica com o aumento das taxas de desemprego, deflagrado pelas mudanças tecnológicas na esfera da produção, foi consideravelmente reforçado pelas novas vantagens comparativas.

3. A globalização favorece, em alguma medida, o declínio dos salários reais dos trabalhadores não-qualificados. Tais trabalhadores permanecem, em média, 
menos tempo no emprego, recebem treinamento durante período mais reduzido e são atingidos por fortes perdas salariais. ${ }^{26}$

Esse quadro alimenta as pressões protecionistas para a imposição de barreiras às exportações dos países em desenvolvimento, entreabrindo a possibilidade de que venha a se agravar o contencioso comercial nesse terreno. Se as diferenças de padrões trabalhistas tendem a desempenhar papel cada vez mais proeminente nas disputas internacionais, a principal questão que se afigura consiste em identificar que instrumentos serão usados para solucionar esses conflitos. Nessa linha cabe indagar se prevalecerão os meios unilaterais em que os governos lançam mão de normas instituídas pelo ordenamento jurídico interno, sobretudo pela legislação comercial, a exemplo do que sucede com os EUA, ou se predominarão as instâncias multilaterais surgidas do assentimento das partes.

Os EUA e vários países desenvolvidos insistem em que a Organização Mundial do Comércio, OMC, é o foro adequado para tratar do tema da "cláusula social" Esta tese, como é fácil perceber, revela inconvenientes e dificuldades. Primeiro, porque a proposta, que não-conta nem mesmo com a concordância de todas as nações desenvolvidas, é ardentemente repelida pelos países em desenvolvimento. Segundo, porque a vocação eminentemente comercial da OMC não-aconselha que ela venha a se ocupar também de assuntos trabalhistas. $O$ temor dos países em desenvolvimento reside nos riscos de que a vinculação entre interesses comerciais e questões trabalhistas desencadeie iniciativas protecionistas em larga escala, comprometendo gravemente as suas exportações.

Em terceiro lugar, conferir à OMC a função de investigar e punir os Estados que exportam bens produzidos em desconformidade com regras destinadas a promover o intercâmbio comercial de acordo com a perspectiva dos países desenvolvidos não-significa genuína preocupação com os Direitos Humanos. A mera repressão, nesse caso, em nada ajudaria a superar os problemas sociais do mundo em desenvolvimento, razão última do desrespeito aos Direitos Trabalhistas reconhecidos internacionalmente. Sem programas de cooperação técnica, que viabilizem o desenvolvimento econômico, não é possível qualquer evolução consistente dos padrões trabalhistas internos. O objetivo de dotar a OMC de competência punitiva

26. Jagdish Bhagwati, Arthur Lehman, The Global Age: From a Sceptical South to a Fearful North, Printed at United Nations, Geneva, June 1997, pp. 10-11. 
nessa área exprimiria o protecionismo das nações desenvolvidas receosas da perda de vantagens comparativas em certos domínios.

Finalmente, tratar a desobediência a Direitos Trabalhistas como simples práticas desleais de comércio importaria em perverter a noção de Direitos Humanos. Seria equipará-la a expedientes econômicos voltados ao aumento da competitividade, graças ao desvirtuamento das regras de mercado, e não visualizá-la como obstáculo à realização da dignidade humana.

No plano acadêmico, Daniel S. Ehrenberg, em artigo recente, sugere a criação de um regime multilateral que reúna a participação conjunta da OIT e do GATT-OMC para prevenir e reprimir a violação dos Direitos Trabalhistas que interferem no comércio internacional. ${ }^{27} \mathrm{~A}$ OIT concorreria com a competência alcançada nas áreas da cooperação técnica e da supervisão, ao passo que a OMC contribuiria com a experiência obtida em matéria de práticas desleais de comércio e com o seu sofisticado sistema de solução de controvérsias, além do respectivo procedimento de implementação das decisões adotadas.

O regime a ser criado se desdobraria em duas fases distintas. A primeira fase (determination phase) consistiria em determinar se houve violação dos Direitos Trabalhistas na produção dos bens que integram a pauta do comércio internacional. Já a segunda (remedial phase) se concentraria na indicação das medidas programas de cooperação técnica, procedimentos de certificação e eventuais penalidades necessárias para eliminar as infrações cometidas, fixando-se o prazo para o seu cumprimento. Gozariam de legitimidade para promover reclamações os Estados, sindicatos patronais e trabalhistas.

Proposta a reclamação, caberia a um comitê permanente, composto por nove membros quatro designados pela OIT, quatro escolhidos pela OMC e um indicado por ambas as organizações, pronunciar-se sobre a admissibilidade da queixa formulada. A reclamação, uma vez admitida, originaria a instalação de um pannel para a solução de disputas formado pela OMC e OIT. O pannel, constituído por sete membros, cuja escolha obedeceria aos mesmos critérios para a composição do comitê de admissibilidade, incumbir-se-ia da preparação de um relatório abordando todas as questões suscitadas pela queixa. O relatório especificaria o período de tempo razoável para o cumprimento das recomendações apresentadas,

27. Daniel S. Ehrenberg, "From Intention to Action An ILO-GATT/WTO Enforcement Regime for International Labor Rights" in Human Rights, Labor Rights, and International Trade. Edited by Lance A. Compa and Stephen F. Diamond, University of Pennsylvania Press, USA, 1996, pp. 163 e ss. 
bem como programas de assistência técnica, procedimentos de certificação e possíveis contramedidas.

Persistindo as violações, seria estabelecido o remediation committee, com a atribuição de deliberar sobre o prazo para os governos cumprirem as providências propostas e para a execução de contramedidas e sanções econômicas.

A cooperação entre a OIT e a OMC operar-se-ia no curso de ambas as etapas. Na primeira fase competiria à OIT apurar as infrações aos Direitos Trabalhistas, devendo a OMC analisar o seu impacto para os fluxos comerciais, analogamente ao que acontece nos casos de dumping ou subsídios. Na segunda fase, a coordenação entre a OIT e a OMC seria igualmente decisiva, já que nenhuma delas estaria em condições de administrar isoladamente qualquer das fases. Esta cooperação proporcionaria benefícios mútuos, criando sinergias positivas e permitindo a apreciação mais ampla da relação entre comércio e práticas trabalhistas.

As contramedidas e sanções econômicas seriam usadas unicamente na hipótese de fracasso de outros meios menos drásticos. Inicialmente, deveria ser levado a efeito um programa de cooperação técnica administrado pela OIT. Programas de certificação se destinariam a assegurar que os produtos elaborados com a violação dos Direitos Trabalhistas não-participassem do comércio internacional.

A aplicação das contramedidas e sanções econômicas teriam lugar em situações extremas, intensificando-se no decorrer do tempo.

Esta proposta representa meritório esforço para superar o impasse hoje existente. Não-obstante a criatividade que exibe, dificilmente contaria com o apoio da comunidade internacional. Os países em desenvolvimento, que formam a esmagadora maioria nas organizações internacionais, rejeitam qualquer participação da OMC na apuração de infrações aos Direitos Trabalhistas.

Parece mais plausível, por isso, quer por razões funcionais, quer por motivos de prudência política, que a OIT se converta em foro privilegiado para o tratamento da violação dos Direitos Trabalhistas. Desde a sua criação, a OIT vem dedicando-se à tarefa de definir os Direitos Trabalhistas, empenhando-se em prol da sua aceitação internacional. A meta de acompanhar a evolução dos acontecimentos nesse campo conduziu à elaboração de um complexo sistema de monitoramento, que compreende a apresentação de relatórios pelos Estados e a análise destes pelo Comitê de Especialistas, o questionamento dos representantes estatais na conferência 
anual da OIT, visitas aos países-membros e a publicação das violações dos Direitos Trabalhistas reconhecidos internacionalmente.

Esse sistema possibilitou avanços significativos, a despeito das deficiências que apresenta. Verificou-se, em número apreciável de Estados, melhoria acentuada das condições de trabalho, após a ratificação das convenções celebradas sob os auspícios da OIT. Estados cujo comportamento fora objeto de censura voltaram a receber assistência da OIT ou estabeleceram contato mais estreito com esta no momento em que ocorreram mudanças políticas internas.

A carta constitutiva da OIT, porém, não-autoriza o uso da força armada ou de sanções econômicas contra o Estado que não-acate as suas decisões. À semelhança das demais organizações internacionais que cuidam dos Direitos Humanos, ela deve confiar, em última instância, no cumprimento voluntário das recomendações que fizer.

A falta de enforcement powers é, sem dúvida, fator limitante para a eficácia dos Direitos Trabalhistas no âmbito internacional. Esta é, aliás, uma das causas principais que levou os EUA e diversos outros países desenvolvidos a considerá-la foro inadequado para o tratamento da "cláusula social"

As evidências sugerem a necessidade de dotar a OIT de um sistema sancionatório mais efetivo, voltado simultaneamente para a consecução de objetivos éticos no domínio dos valores e para a repressão das infrações aos Direitos Trabalhistas, enquanto Direitos Humanos. Mais do que prever medidas punitivas, utilizadas apenas em situações excepcionais, é necessário que a reforma a ser introduzida vise contemplar programas mais ambiciosos de cooperação técnica, abrangendo a reformulação da legislação doméstica, a imposição de penalidades mais severas às transgressões cometidas, o aperfeiçoamento dos instrumentos de ação estatal, estímulos a campanhas de educação pública, desenvolvimento de processos produtivos mais eficientes, programas de alfabetização e de erradicação da pobreza.

No contexto atual, a tendência com maior probabilidade de se consolidar no plano multilateral é deixar à OIT a competência para lidar com o tema da violação dos Direitos Trabalhistas, aprimorando-se os mecanismos de implementação das decisões adotadas. O êxito dessa tendência depende, porém, da superação de alguns desafios.

Seria necessário, em primeiro lugar, fortalecer os programas de cooperação técnica capazes de propiciar o cumprimento dos tratados e convenções 
internacionais. O financiamento desses programas exige recursos, e somente poderiam ser obtidos se houvesse maior disposição de fornecê-los por parte das nações desenvolvidas.

Em segundo lugar, as sanções existentes teriam de ser ao mesmo tempo politicamente viáveis e exeqüíveis na prática. A dificuldade, nesse âmbito, é estabelecer que tipos de sanção os países estão dispostos a aceitar, já que algumas delas poderiam ter reflexos negativos sobre suas exportações. Proibir a negociação de um produto no mercado internacional por ter sido elaborado com o emprego de mão-de-obra infantil provoca muitas vezes efeitos indesejáveis, concorrendo para agravar o desemprego, estimular a prostituição e elevar os índices de criminalidade.

É evidente que a OIT não estaria em condições de cercear as vantagens comparativas que os países em desenvolvimento auferem em função da existência de padrões trabalhistas distintos. Ela se desfiguraria se fosse utilizada para impor a equalização dos custos mediante regimes trabalhistas que eliminem as vantagens comparativas dos países em desenvolvimento.

Deve-se advertir, por outro lado, que a eficácia de tal sistema requer a adesão das nações desenvolvidas. Sem o comprometimento com as regras multilateralmente acordadas, a adoção de medidas unilaterais tenderia a aumentar, ampliando-se o protecionismo. Sob o pretexto de atuar na defesa de padrões trabalhistas mais eqüitativos, a expansão do "unilateralismo agressivo" teria como resultado prático transferir parte dos problemas advindos com a perda das vantagens comparativas do norte em certas áreas, o que contribuiria para deteriorar ainda mais a exclusão social do Sul.

São Paulo, março de 1999. 